\title{
Monitoring activities following the grounding of the MSC Napoli in Lyme Bay, UK, in 2007
}

\author{
R. J. Law \& C. Kelly \\ The Centre for Environment, Fisheries and Aquaculture Science (Cefas), \\ UK
}

\begin{abstract}
On $18^{\text {th }}$ January 2007 , severe storms and huge waves battered the MSC Napoli outbound from Europe along the English Channel, seriously damaging its hull. Eighty $\mathrm{km}$ south of the UK coast, severe cracks developed in both sides of the hull and flooded the engine room. The crew abandoned ship and were airlifted to safety. The ship was taken in tow by two emergency towing vessels maintained on station by the UK and French governments and set off for Portland Harbour. Unfortunately the condition of the ship worsened and, amid fears that she may sink offshore, was beached $1 \mathrm{~km}$ off Branscombe Beach in Devon, within Lyme Bay. This area is part of Britain's first World Heritage Site (the Jurassic Coast), and of high nature conservation importance. The vessel was carrying over 40,000 tonnes of cargo in 2,318 containers. Of these, 159 contained 1,684 tonnes of dangerous goods as classified by the IMO criteria. These included a wide variety of industrial and agricultural chemicals such as pesticides, fumigants, solvents and personal care products. As a component of the UK response, a monitoring programme was established, involving bodies such as Cefas, the Environment Agency, Natural England, the Plymouth Marine Laboratory, and the University of Plymouth, with overall co-ordination by Cefas. As well as one-off surveys, regular monitoring was undertaken of waters around the coast of the bay and of crabs and scallops collected during routine fishing activities in Lyme Bay, along with farmed mussels from Portland Harbour. Chemical analysis and toxicity testing of waters from the ship's holds and engine room were also conducted routinely to monitor the risk from water being released to the bay. The overall impact of the incident was less than first feared. Keywords: oil and chemical spill, MSC Napoli, Lyme Bay, monitoring, PAH.
\end{abstract}




\section{Introduction}

On $18^{\text {th }}$ January 2007 , severe storms and huge waves battered the container ship MSC Napoli en route from Antwerp to South Africa. Eighty km south of the UK coast at Lizard Point, in the English Channel, severe cracks developed in both sides of the hull and flooded the engine room. The crew abandoned ship and were airlifted to safety; the ship was taken in tow by two emergency towing vessels maintained on station by the UK and French governments and set off for Portland Harbour. Unfortunately the condition of the ship worsened and, amid fears that she may sink offshore, was beached $1 \mathrm{~km}$ off Branscombe Beach in Devon, within Lyme Bay. This area is part of Britain's first World Heritage Site (the Jurassic Coast) and is of high nature conservation importance.

The MSC Napoli was carrying over 40,000 tonnes of cargo in 2,318 containers. Of these, 159 contained 1,684 tonnes of dangerous goods as classified by the IMO criteria. These included a wide variety of industrial and agricultural chemicals such as pesticides, fumigants, solvents and personal care products. The vessel also carried around 3,500 tonnes of heavy fuel oil (IFO380) and 500 tonnes of marine diesel oil as bunkers. Initially, this was considered to present a greater risk to the local environment than elements of the cargo.

As the ship grounded and over the next few days, approximately 100 containers were lost overboard from the deck cargo. Of these, 76 came ashore and were dealt with on the beach and the remainder were presumed sunk. These were recovered later using sonar surveying to locate the containers and divers to attach lifting gear. None of these containers carried dangerous goods as all of those containers were carried in the holds of the vessel. Work began to remove the fuel oils and containers from the vessel. The oils were transferred to a lightening tanker and the containers taken by barge to Portland Port, where a system had been set up to handle them. This involved assessing the state of both the containers and their contents, and either recovering, recycling or disposing of them, depending upon their condition. By 26 February all of the oil and all the containers above deck had been removed. The final container from the hold cargo was removed on 17 May, four months after the start of the incident. On the 9 July, the ship was refloated with the intention of towing her to a port for recycling. However, a diver survey showed that the ship's condition was too poor for her to survive a tow and she was regrounded on 13 July a short distance from the original grounding site. On 20 July, shaped explosive charges were used to separate the ship into two parts. The floating bow section was towed to Belfast for recycling, leaving the flooded stern aground. At the time of writing, work continues to dismantle parts of the stern. By mid-November, the accommodation block, hold covers and other materials had been removed and the intention is to lift and remove the final remaining section by April 2008.

\section{Monitoring activities}

Immediately following the grounding, it was apparent that a significant quantity of oil had been lost from the vessel and, with a continuing threat of the release of 
toxic chemicals from the cargo, it was decided to initiate a monitoring programme across Lyme Bay. This involved Cefas, the Environment Agency, Natural England, the Plymouth Marine Laboratory and the University of Plymouth; with overall co-ordination by Cefas. Each of these organisations had their own focus, based on their individual environmental responsibilities, but these were complementary and built into a comprehensive monitoring programme. A full report of the monitoring activities is being prepared and will be available from the Cefas website [1]. Initially, monitoring focussed on the spilled oil, but plans to allow monitoring of any lost chemicals against a sediment baseline were also put in place early on. As it was not possible to know which chemicals would need to be monitored until they were lost to sea, it was decided to collect and archive surface sediment samples at $-20^{\circ} \mathrm{C}$ against future need. Cefas and the Environment Agency collected these coastal sediment samples, around the whole of Lyme Bay from Teignmouth to Portland Harbour. The Plymouth Marine Laboratory collected offshore samples during the cruise described in section 2.3. The Environment Agency also collected samples close to the vessel. Figure 1 shows the sampling locations.

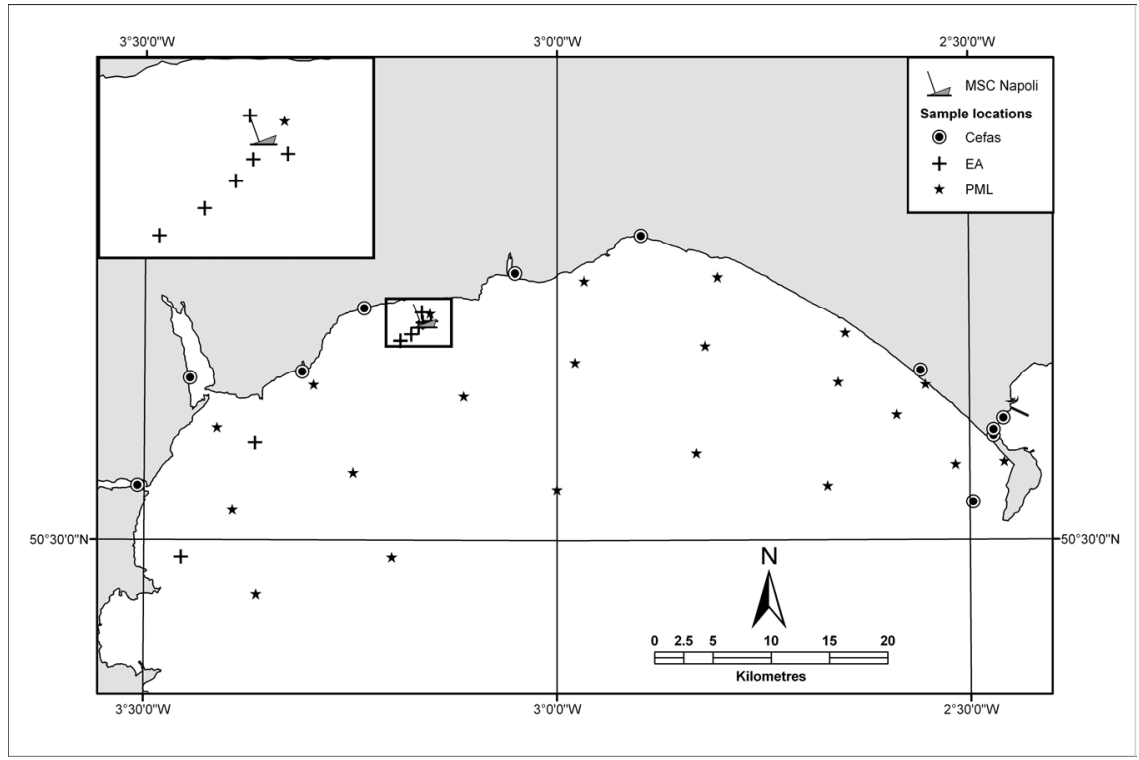

Figure 1: Sampling locations for baseline sediments to be archived frozen.

\subsection{Environment Agency}

The Environment Agency based their sampling programme on a routine bathing water quality scheme, which was already in operation, supplemented by additional stations in order to enhance the coverage. Seawater samples were analysed for a series of routinely determined target compounds, including hydrocarbons and polycyclic aromatic hydrocarbons (PAHs) and additionally 
conducted screening analyses using coupled gas chromatography-mass spectrometry in order to detect and quantify non-target chemicals. A large number of chemicals were identified at trace concentrations (low or sub- $\mu \mathrm{g}$ per litre levels). These included one-ring aromatic compounds (benzene, toluene and xylenes), bisphenol A, other phenols, bromoform, caffeine, iso-propyl alcohol and other alcohols, tributyl phosphate, trichloroethylene and a range of phthalate esters. Most were not, however, included within the cargo aboard MSC Napoli, and these findings probably largely reflect low-level coastal pollution normally present in the area. As part of the control activities associated with the incident, water samples were taken routinely from the holds and engine room of the vessel. These were also analysed by the Environment Agency. A number of chemicals were identified at concentrations an order of magnitude or higher than the relevant EQS (environmental quality standard, based on continuous exposure), and these were contained within the cargo. Parallel toxicological studies undertaken by Cefas generally indicated low levels of acute toxicity to an alga and a crustacean, and dispersion modelling suggested that this toxicity would be reduced rapidly following release of water from inside the ship to the wider marine environment [2]. Surface sediments, limpets and mussels were collected from sites between Brixham and Portland Bill and archived as above. The Environment Agency are also preparing a stand-alone report of their activities which will be made available via their website.

\subsection{Cefas}

Sediment samples to be archived were collected during the last week of January 2007. The major part of Cefas' activities were focussed on the determination of hydrocarbon and PAH concentrations in commercial shellfish across Lyme Bay and in Portland Harbour. Sampling began on 24 January, with shellfish being purchased from commercial catches. The species studied were edible and spider crabs, mussels and scallops. Sampling locations across Lyme Bay are shown in Figure 2. Tissue samples were analysed using well-established methodology with appropriate analytical quality control [3]. Briefly, tissue samples were subjected to alkaline digestion followed by liquid-liquid extraction and alumina clean-up, with analysis of a suite of PAH (both parent and alkylated) using coupled gas chromatography-mass spectrometry. A number of internal standards (deuterated PAH) were added at the start of the digestion, and both procedural blanks and laboratory reference materials (LRMs) were analysed within each sample batch. The results obtained for the LRMs were used for acceptance or rejection of the results for each sample batch and also to construct quality control charts to allow the day-to-day performance of the method to be assessed.

Over 50 individual shellfish samples were analysed. Summed PAH concentrations ranged from 7 to $229 \mu \mathrm{g} / \mathrm{kg}$ wet weight, with the highest concentration observed in scallops reared in Portland Harbour which was unaffected by this incident but has been subjected to a number of small oil spills in the past. Concentrations in scallops and in one sample of mussels were slightly higher than those in crabs, but only samples collected very close to the wreck (but outside the $500 \mathrm{~m}$ exclusion zone) showed signs of contamination 
from the spilled oil. Even in these samples, concentrations were only slightly elevated relative to the general background. The UK Food Standards Agency has set guideline values for three individual PAH compounds in order to protect human health $(10 \mu \mathrm{g} / \mathrm{kg}$ wet weight for benzo[a]pyrene and $15 \mu \mathrm{g} / \mathrm{kg}$ wet weight for both benz $[a]$ anthracene and dibenz $[a, h]$ anthracene) and these were not breached. These three compounds were not detected in any of the crab samples.

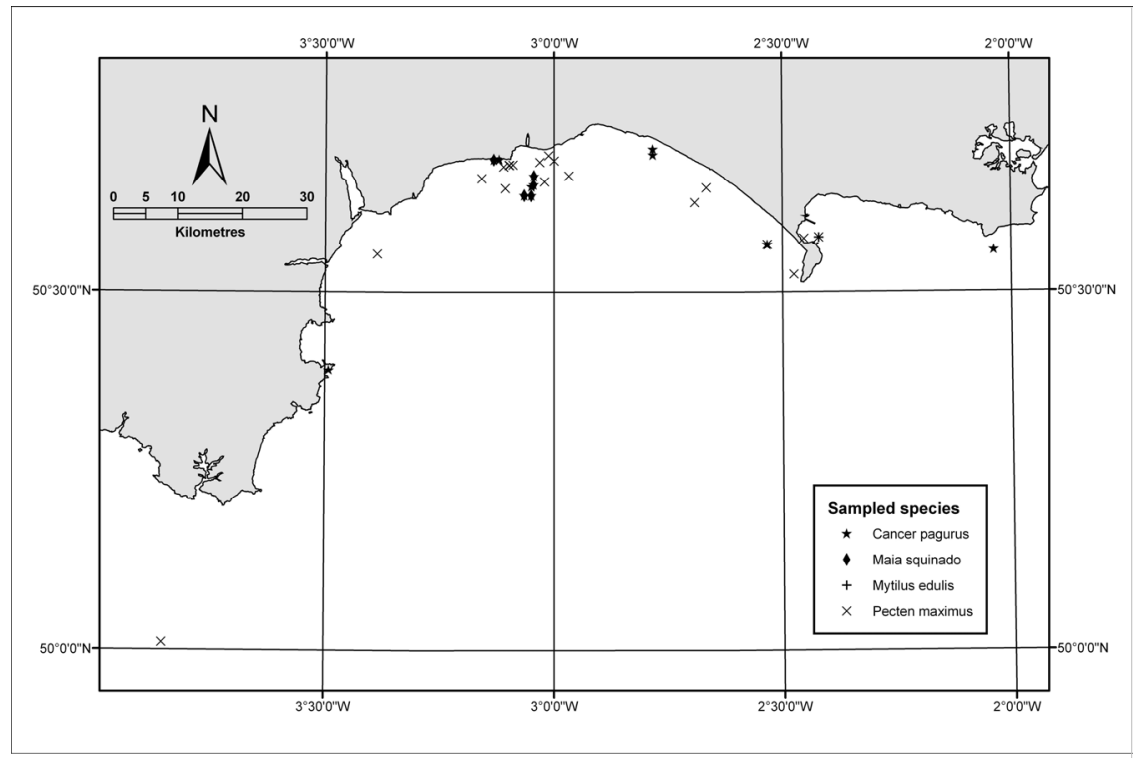

Figure 2: $\quad$ Sampling locations for the commercial shellfish samples analysed for hydrocarbons and PAH by Cefas.

In 1996-97, we undertook a survey of PAH concentrations from commercial shellfish beds around England and Wales. No scallops were analysed but, in mussels, summed PAH concentrations ranged from 40 to $11,500 \mu \mathrm{g} / \mathrm{kg}$ wet weight. The concentrations observed in Lyme Bay in 2007 are at the lower end of this range, although the earlier samples were exposed only to diffuse pollution and local point sources. Following the oil spill from the Sea Empress in Wales in 1996, mussels from many sites within the fishery closure area showed summed PAH concentrations above $1,000 \mu \mathrm{g} / \mathrm{kg}$ wet weight and the highest concentrations observed, within Milford Haven, were $>100,000 \mu \mathrm{g} / \mathrm{kg}$ wet weight [4].

\subsection{Plymouth Marine Laboratory}

Once oil had been spilled in Lyme Bay following the grounding of MSC Napoli it became necessary to conduct a survey aimed at assessing the degree of contamination and its spread. The Environment Agency were analysing water samples taken from the coast, but it was decided to supplement this by mounting 
a dedicated offshore cruise. Scientists from the Plymouth Marine Laboratory conducted this cruise on 30 - 31 January 2007. A series of samples of subsurface water and of the sea surface microlayer were taken at sites across the whole of Lyme Bay, approximately along the $10 \mathrm{~m}, 20 \mathrm{~m}$ and $40 \mathrm{~m}$ depth contours (Figure 3 ). In addition, samples of surface sediment were taken and stored frozen at -20 ${ }^{\circ} \mathrm{C}$ as baseline samples, in case sediment monitoring was to be conducted at a later stage. Samples from the sea surface microlayer were obtained using a surface slick sampler [5], and the subsurface water samples were obtained at 2 meters depth with 2.5 litre Winchester amber glass bottles using a custom-made stainless steel and Teflon sampling device [3]. Analyses were conducted using coupled gas chromatography-mass spectrometry following solvent extraction and clean-up.

In general, the PAH concentrations observed in the subsurface seawater samples were low and probably represented the normal background in Lyme Bay. The highest concentrations was observed at station 5, closest to the grounded MSC Napoli, where a modestly elevated concentration was seen. In the surface microlayer samples a similar pattern was observed, reflecting a clear (though localised) petrogenic contamination due to the oil released from the ship. Beyond the localised area of the spill, PAH from pyrolytic sources were more dominant in the subsurface waters, reflecting the general background contamination of Lyme Bay [6].

\subsection{Natural England}

Lyme Bay is an area of high nature conservation importance, particularly in relation to subtidal reef habitats and species such as the pink sea fan (Eunicella verrucosa), a soft coral. In order to protect the seabed, scallop dredging has been voluntarily discontinued in a number of areas within the bay. There was a concern that the ship and/or the lost containers may damage important seabed features, and Natural England commissioned two benthic surveys in order to assess possible impacts. The first of these was undertaken during June 2007. Four sites were surveyed by divers (Beer Home Ground, West Tennants Reef, Dogleg Reef and Sunset Ledge). Beer Home Ground was assessed as highly degraded due to earlier scallop dredging activities. The other three sites showed much more diverse fauna and showed no signs of recent impacts when compared to earlier studies undertaken in 2004 or 2006. The second survey was undertaken during August 2007, and involved the use of a drop-down video system to survey the seabed. The area surveyed included the immediate vicinity of the MSC Napoli and four adjacent reef areas (Beer Home Ground, West Tennants Reef, Eastern Heads and Pinhay Settle). No obvious signs of contamination or physical damage from the MSC Napoli could be seen on any of the reefs. Some physical damage was noted on West Tennants Reef, but this was thought to be due to the earlier use of mobile fishing gear. Some debris was observed on the seabed relatively close to the MSC Napoli, but no signs of physical damage from this debris moving around could be seen on the video images. Some oiling of static fishing gear was also observed. 
Oil spilled from the MSC Napoli resulted in over 3,000 seabird casualties. Natural England contracted the British Trust for Ornithology to undertake necropsies of approximately $10 \%$ of these (306 birds) in order to assess the impact on populations of seabirds affected [7]. Of these, 168 were guillemots and 104 razorbills (55\% and 34\%, respectively). Of the guillemots that could be aged, $77 \%$ were adults, $20 \%$ were young adults and only $3 \%$ were sub-adults. The effects of the removal of breeding adults will impact on the southern populations that breed in Iceland, the Færoes, Britain, Ireland and France. Analysis of solvent swabs from oiled feathers from 13 birds was undertaken at Cefas, and fingerprinting studies confirmed that the oil on 12 of the feathers was fuel oil from the MSC Napoli. Chromatograms are shown in Figures 3a and $3 \mathrm{~b}$.

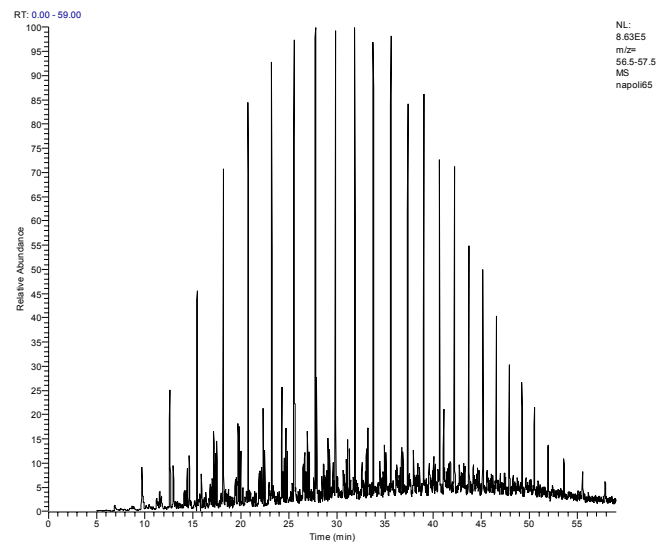

(a)

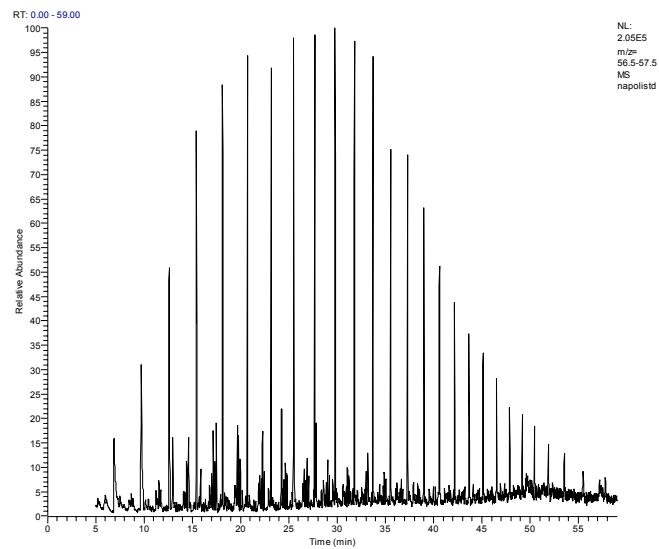

(b)

Figure 3: (a) GC-MS total ion chromatogram of a solvent swab of an oiled feather from seabird number 65. (b) GC-MS total ion chromatogram of IFO380 heavy fuel oil from MSC Napoli. 
Lyme Bay represents one of only three UK sites at which the endangered scaly cricket (Pseudomogoplistes vicentae) can be found. These animals inhabit shingle above the high-water mark, and are associated with the seaweed strandline. Obviously, they will have been at risk from both beached oil and containers and debris, which came ashore, and from recovery activities on the beaches. Once the MSC Napoli has been removed and all other related operations have ceased, a survey of the scaly cricket will be conducted.

\subsection{University of Plymouth}

In collaboration with the Plymouth Marine Laboratory, the University of Plymouth used combined biological effects monitoring techniques and chemical fingerprinting to undertake a rapid assessment of the impact of spilled oil and chemicals on the adjacent coastline. During January 2007, although oil contamination appeared to be restricted to a surface slick in the vicinity of the wreck, biomarkers of cytotoxicity and immunotoxicity (cell viability and phagocytosis, respectively) were reduced in samples of common limpets from Branscombe beach, close to the wreck [8]. For this study, three locations within Lyme Bay were studied, and two reference sites in Cornwall and Devon were sampled for comparative purposes. A second collection of limpets and winkles was made during July, around the time when explosives were used to break the vessel into two parts. Ecotoxicological testing showed further impairment of cellular function in these animals, and chemical fingerprinting using GC-MS indicated that oil swabbed from their shells matched the IFO380 heavy fuel oil carried by the MSC Napoli.

\section{Assessment of impact}

In the event, none of the containers of dangerous goods were lost from the vessel and all were recovered to Portland Port and dealt with on land. Trace quantities of some chemicals carried aboard were detected in the waters within the holds of the vessel, and contributed to low levels of toxicity detected in the same locations [2]. Both declined with time as containers were removed and, by the time the vessel was refloated, had effectively fallen to zero. This meant that the discharge of 58,000 tonnes of water into Lyme Bay during the refloating caused no concern regarding effects in the wider environment. Losses of oil caused pollution of beaches in both Lyme Bay and North Brittany. Over 3,000 seabird casualties were found around Lyme Bay, which will have some impact on the southern breeding populations. Somewhat elevated concentrations of PAH were observed in both subsurface waters, the surface microlayer and shellfish samples collected close to the wreck, but these elevations were modest and very localised. Overall, the impact of the incident was less than feared initially from study of the cargo manifest and toxicity assessment of the chemicals carried aboard the MSC Napoli. One note of caution though for future incidents is that, although the MSC Napoli was a large container ship when constructed in 1991, she is now of a modest size at 4,419 TEU (twenty-foot equivalent units). Coping with a 
casualty from the largest class of vessels currently afloat, which are 14,500 TEU, would be a vastly more difficult undertaking.

\section{Acknowledgements}

The Cefas, Natural England and Plymouth Marine Laboratory contributions to the post-grounding monitoring activities around the MSC Napoli were funded by the Department for Environment, Food and Rural Affairs under research contract ME1308. Studies undertaken by the University of Plymouth were funded by the EU FACE-IT programme on pollution response [9]. The authors would like to thank Markus Diesing for preparing Figures $1 \& 2$, and Carlos Guitart, Giles Bryan and Tamara Galloway for providing details of their organisations' research programmes. This article is C British Crown copyright 2008.

\section{References}

[1] Law, R.J. (compiler). Environmental monitoring conducted in Lyme Bay following the grounding of MSC Napoli in January 2007, with an assessment of impact. Science Series Aquatic Environment Monitoring Report, Cefas Lowestoft, in preparation.

[2] Kirby, M.F., Devoy, B., Law, R.J. \& Ward, A. The use of a bioassay based approach to the hazard/risk assessment of cargo derived toxicity during shipping accidents: a case study - the MSC Napoli. Marine Pollution Bulletin, in press 2008.

[3] Kelly, C.A., Law, R.J. \& Emerson, H.S. Methods of analysing hydrocarbons and polycyclic aromatic hydrocarbons in marine samples. Science Series Aquatic Environment Protection: Analytical Methods, Cefas Lowestoft, 12: 18pp, 2000.

[4] Law, R.J. \& Kelly, C. The impact of the "Sea Empress" oil spill. Aquatic Living Resources, 17, 389-394, 2004.

[5] Guitart, C., Garcia-Flor, N., Dachs, J., Bayona, J.M. \& Albaiges, J. Evaluation of sampling devices for the determination of polycyclic aromatic hydrocarbons in surface microlayer coastal waters. Marine Pollution Bulletin, 48(5), pp. 961-968, 2004.

[6] Guitart, C., Frickers, P., Horillo-Carballo, J., Law, R.J. \& Readman, J.W. Characterisation of sea surface chemical contamination after shipping accidents. Environmental Science and Technology, in press 2008.

[7] Grantham, M.J. \& Newson, S.E. Post-mortem analysis of bird corpses from the grounding of the MSC Napoli. Research Report 466, British Trust for Ornithology, Thetford, Norfolk, 2007.

[8] Galloway, T.S., Lewis, C., Guitart, C. \& Readman, J.W. Integrated assessment of accidental marine pollution in the English Channel. In preparation.

[9] EU FACE-IT programme, www.face-it.org 